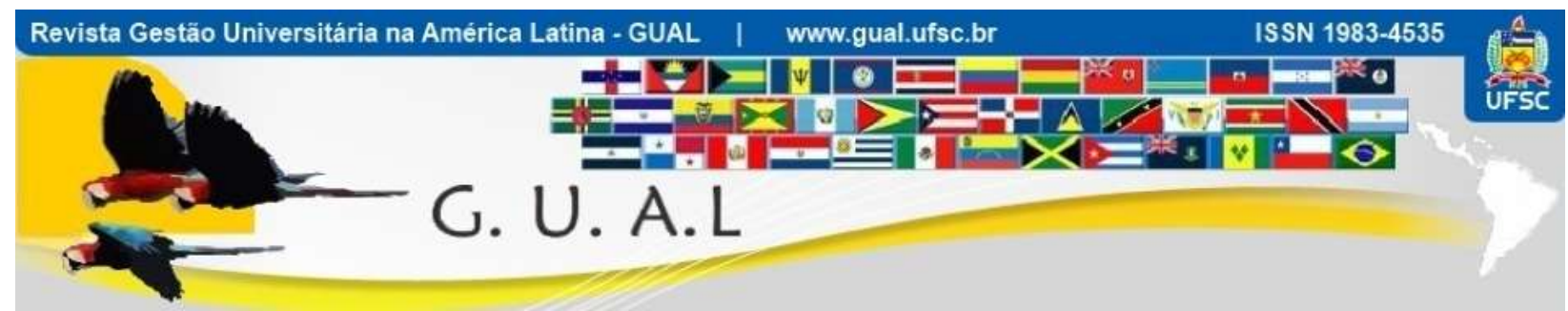

DOI: http://dx.doi.org/10.5007/1983-4535.2020v13n2p116

\title{
AUDITORIA INTERNA E GESTÃO: ESTUDO DE CASO EM UMA UNIVERSIDADE FEDERAL À LUZ DA TEORIA INSTITUCIONAL
}

\section{INTERNAL AUDIT AND MANAGEMENT: A CASE STUDY IN A FEDERAL UNIVERSITY IN THE LIGHT OF THE INSTITUTIONAL THEORY}

Letícia dos Passos Pereira Dias, Mestre http://orcid.org/0000-0003-4919-3854 leticia.ppdias@gmail.com Universidade Federal de Pelotas $\mid$ Auditoria Interna Pelotas | Rio Grande do Sul | Brasil

Débora Gomes de Gomes, Doutora http://orcid.org/0000-0002-7955-0958 debora_furg@yahoo.com.br Universidade Federal do Rio Grande | Instituto de Ciências Econômicas, Administrativas e Contábeis Rio Grande | Rio Grande do Sul | Brasil

Rodrigo Angonese, Doutor http://orcid.org/0000-0002-0854-9925 rangonese@upf.br Universidade de Passo Fundo | Programa de Pós-Graduação em Administração Passo Fundo | Rio Grande do Sul | Brasil

Alexandre Costa Quintana, Doutor http://orcid.org/0000-0001-6896-9465 professorquintana@hotmail.com

Universidade Federal do Rio Grande | Instituto de Ciências Econômicas, Administrativas e Contábeis Rio Grande | Rio Grande do Sul | Brasil

Recebido em 22/maio/2019

Aprovado em 06/fevereiro/2020

Publicado em 01/maio/2020

Sistema de Avaliação: Double Blind Review 


\title{
RESUMO
}

Este estudo tem por objetivo analisar o processo de institucionalização da auditoria interna em uma universidade federal, na perspectiva de auditores e gestores. $\mathrm{O}$ estudo é desenvolvido à luz da Teoria Institucional, com apoio do modelo de análise proposto por Tolbert e Zucker (1998). No que diz respeito aos aspectos metodológicos, a pesquisa é de natureza qualitativa e assume a forma de estudo de caso único. Para coletar os dados, foram realizadas entrevistas com auditores e gestores da alta administração e análise de documental. Os resultados indicam baixa aderência ao estágio de habitualização e moderada aos estágios de objetificação e sedimentação do processo de institucionalização. Verifica-se que a auditoria interna em estudo: conta com boa estrutura física; mantém os procedimentos organizados; acompanhou o processo de modernização da atividade e que há apoio e reconhecimento por parte da alta gestão. Por outro lado, os resultados indicam que há necessidade de esclarecer as finalidades e a forma de atuação do setor na Universidade, de incrementar o processo de acompanhamento das recomendações emitidas e de ampliar o acesso a programas e sistemas de informação.

Palavras-chave: Auditoria Interna. Administração Pública. Controles Internos. Eficácia Organizacional. Teoria Institucional.

\begin{abstract}
This study has an objective to analyze the process of institutionalization of internal auditing in a federal university from the perspective of auditors and managers. The study is developed considering the Institutional Theory, with the support of the model proposed by Tolbert and Zucker (1998). As far as the methodological aspects are concerned, the research is of a qualitative nature and takes the form of a single case study. To collect the data, interviews were conducted with auditors and managers of top management and analysis of documents. The results indicated low adherence to the stage of habitualization and moderate to the stages of objectification and sedimentation of the institutionalization process. It is verified that the internal audit under study has a good physical structure, which keeps the procedures organized, which accompanied the process of modernization of the activity, and that there is support and recognition from top management. On the other hand, the results indicate that there is a need to clarify the purposes and the way the sector operates in the University, to amplify the process of monitoring the recommendations and to improve access to information systems and programs.
\end{abstract}

Keywords: Internal Audit. Public Administration. Internal Controls. Organizational Effectiveness. Institutional Theory. 


\section{INTRODUÇÃO}

O controle é considerado uma das funções básicas da administração (CASTRO, 2011). Segundo Schulz (2014), o controle deve estar presente em todos os níveis hierárquicos, permeando todas as atividades da organização, a fim de assegurar que os objetivos sejam alcançados. Na Administração Pública, o controle vem assumindo uma dimensão cada vez maior. A crise econômica que acomete o país desde 2014, somada às recorrentes notícias envolvendo a malversação de dinheiro público, reforça a necessidade de zelar pelo uso regular e eficiente dos recursos (BORDIN, 2015). Além disso, a cobrança por serviços públicos de qualidade tem sido uma demanda crescente da sociedade (LINCZUK, 2012).

Nas universidades federais, o controle se tornou um aspecto indissociável do fazer institucional. Em função de políticas e programas de expansão universitária, as universidades passaram a gerir um volume de recursos ainda mais expressivo (LINCZUK, 2012). Além disso, cabe destacar o importante serviço social prestado por tais entidades, que são inegáveis agentes de transformação social (SCHULZ, 2014). Assim sendo, o controle deve ser priorizado pelo gestor universitário, não só para segurança do cidadão, mas para seu próprio resguardo contra uma eventual responsabilização por atos irregulares (CASTRO, 2011).

Nesse contexto, destaca-se o trabalho desenvolvido pelas auditorias internas nas universidades e nos demais órgãos da Administração Pública Indireta. As auditorias internas são ferramentas de apoio à gestão que possuem o controle em sua essência, atuando na prevenção de falhas e na busca da eficácia organizacional (SCHULZ, 2014). Em consonância com normas e práticas internacionais, as auditorias internas devem desempenhar uma atividade voltada à melhoria dos processos de governança, de gerenciamento de riscos e de controles internos da instituição (CGU, 2017). Por meio de avaliações e consultorias envolvendo esses e outros processos, cabe à auditoria interna procurar mostrar os melhores caminhos ao gestor público (MARÇOLA, 2011).

Acredita-se que para ter efetividade e conseguir agregar valor à organização, é importante que a auditoria interna esteja institucionalizada no ambiente em que atua. Primeiro porque o auditor precisa da cooperação do auditado, que é quem detém o conhecimento operacional do serviço e, segundo, porque as recomendações não são obrigatórias e uma recomendação não atendida representa falta de efetividade do trabalho desenvolvido (CASTRO, 2011). 
Considera-se que uma estrutura está institucionalizada quando é tida como natural e "assumida como certa" pelos atores sociais envolvidos (JEPPERSON, 1999). O estudo dos fatores externos e internos que levam à institucionalização é realizado por meio da Teoria Institucional, que busca explicar como e por que formas organizacionais adquirem condição de valores e se tornam legitimadas nas estruturas sociais (TOLBERT; ZUCKER, 1998; BERGER; LUCKMANN, 2004). Para Tolbert e Zucker (1998) até se tornarem institucionalizadas as formas organizacionais passam por um processo.

Desta forma, o objetivo deste estudo é analisar o processo de institucionalização da auditoria interna em uma universidade federal com apoio do modelo proposto por Tolbert e Zucker. A justificativa da pesquisa reside na relevância social e econômica do serviço prestado pelas universidades (CHIARINI; VIEIRA, 2012; SCHULZ, 2014) e na posição estratégica ocupada pela auditoria interna (CASTRO, 2011), que precisa estar solidamente estabelecida para alcançar os resultados esperados.

Acredita-se que este estudo, além de ter o potencial de influenciar análises organizacionais que contribuam para o fortalecimento da estrutura analisada, pode ser capaz também de induzir outras auditorias internas da Administração Pública a refletirem sobre a adoção de estratégias e práticas. Além disso, a partir dos resultados desta pesquisa, entende-se que pode ser ampliada a base de conhecimentos sobre os fatores que levam à institucionalização de formas organizacionais, sobretudo em relação ao tipo de estrutura analisada neste estudo.

Este artigo está estruturado em cinco seções, incluindo esta introdução. Na sequência, apresenta-se o referencial teórico abordando as auditorias internas na Administração Pública e a Teoria Institucional. Em seguida, descreve-se a metodologia adotada, os resultados e a conclusão do estudo.

\section{REVISÃO DE LITERATURA}

\subsection{AUDITORIAS INTERNAS NA ADMINISTRAÇÃO PÚBLICA FEDERAL INDIRETA}

O controle na Administração Pública é exercido pelo controle externo - especialmente pelo Congresso Nacional com o apoio do Tribunal de Contas da União (TCU) - e pelo sistema de controle interno no âmbito de cada um dos três poderes constituídos (BRASIL, 1988). O sistema de controle interno do Poder Executivo Federal tem como órgão central o Ministério da Transparência e Controladoria Geral da União (CGU) (CASTRO, 2011). 
Para auxiliar no desempenho de suas funções, a CGU conta com o apoio de assessorias especiais de controle interno no âmbito de cada Ministério (BRASIL, 2000). Ainda, considerando a amplitude e a estrutura descentralizada da Administração Pública, o Governo Federal tornou obrigatória a criação de auditorias internas ou ao menos a designação formal de um servidor como auditor interno na estrutura dos órgãos da Administração Pública Federal Indireta.

De acordo com o art. 14 do Decreto n. ${ }^{\circ} 3.591 / 2000$ (BRASIL, 2000), as auditorias internas possuem como finalidades básicas o fortalecimento da gestão e a racionalização das ações de controle. A atividade de auditoria interna tem em sua essência a busca do fortalecimento dos controles internos a um custo razoável para a instituição (SOUZA et al., 2013). Marçola (2011) define controles internos como os mecanismos utilizados pela gestão a fim de fornecer segurança em relação ao alcance dos objetivos.

A auditoria interna também deve avaliar se as leis e regulamentos estão sendo atendidos pela instituição, caracterizando a auditoria de "conformidade. Igualmente, em sua conotação mais moderna, a auditoria deve se preocupar com os aspectos gerencias e de resultado das entidades realizando "auditorias operacionais", a fim de verificar se os recursos estão sendo utilizados de forma eficiente e se os objetivos traçados pela instituição estão sendo alcançados (SCHULZ, 2014).

É importante destacar que as atividades da auditoria interna devem ser planejadas. Nas entidades da Administração Pública Indireta, as ações de auditoria a serem realizadas devem constar no Plano Anual de Atividades de Auditoria Interna (PAINT) a ser elaborado para execução no exercício seguinte. Conforme a Instrução Normativa (IN) no 24/2015 da CGU, o PAINT deve conter os temas e macroprocessos a serem auditados classificados por meio de uma matriz de risco, informando os objetivos, os prazos e os recursos disponíveis para cada ação (CGU, 2015). Ao final de cada exercício, deve ser elaborado o Relatório Anual de Atividades de Auditoria Interna (RAINT) contemplando o resumo das atividades realizadas ao longo do ano.

Buscando convergência com normas internacionais, a CGU em conjunto com o Ministério do Planejamento (MP), por meio da Instrução Normativa $n^{\circ}$ 01/2016, determinou a adoção sistematizada de práticas relacionadas à gestão de riscos, aos controles internos e à governança pelos órgãos do Poder Executivo Federal (MP; CGU, 2016). A partir da referida IN, complementada pela $\mathrm{IN} \mathrm{n}^{\circ} 03 / 2017$ da CGU (CGU, 2017), as atribuições da auditoria 
interna foram oficialmente incrementadas com a função de avaliar e melhorar a eficácia desses processos, que passaram a ocupar posição central na atividade.

Diante da convergência com normas internacionais, nova ênfase foi atribuída à atividade, com foco nos riscos do negócio e nas práticas de governança corporativa. Passou a ser exigida uma postura mais proativa e criativa do auditor, transcendendo ao simples apontamento de erros. No entanto, apesar da nova abordagem, a relação entre auditor e auditado ainda representa um ponto nevrálgico na atividade, que precisa ser aprimorado (CASTRO, 2011; SCHULZ, 2014).

Em que pese a auditoria interna não tenha um viés impositivo ou punitivo, conforme expõe Marçola (2011), e sim de assessoramento à gestão, ainda é comum o auditor ser visto pelo auditado com algumas reservas. Esse posicionamento de defesa do auditado é agravado ainda pela falta de conhecimento sobre os propósitos da atividade (MARÇOLA, 2011). Nessa perspectiva, alguns estudos empíricos apontam que ainda há uma visão distorcida em relação aos propósitos da auditoria interna (SANTANA, 2013; SCHULZ, 2014; BORDIN, 2015).

O cenário revelado por pesquisas na área reforça que a relação entre auditor e auditado ainda precisa ser aprimorada. Vale dizer que a cooperação do auditado é essencial para qualidade do trabalho, uma vez que é ele quem detém o conhecimento operacional do serviço. Além disso, as recomendações não são obrigatórias e uma recomendação não atendida representa falta de efetividade do trabalho desenvolvido (CASTRO, 2011).

Desta forma, para deixar o lugar que auditou melhor do que quando encontrou, o auditor precisa deixar claros os propósitos de sua atuação e ao revelar as fragilidades, deve encontrar uma solução que encoraje os responsáveis a agir (SOUZA et al., 2013). Em última análise, para que a auditoria interna consiga agregar valor à organização, percebe-se que é necessário que os gestores e, principalmente, a alta administração, tenham consciência dos benefícios gerados pela atividade.

\subsection{TEORIA INSTITUCIONAL}

A Teoria Institucional se desenvolveu em diferentes campos do conhecimento, sendo possível distinguir ramificações na Economia, na Política e na Sociologia. A vertente sociológica da teoria institucional é predominante nos estudos organizacionais (ALVES, 2012) e compreende a abordagem teórica adotada nesse estudo. 
Segundo Peci (2005), os primeiros estudos organizacionais adotavam o conceito de instituição de um modo prescritivo. Nesse sentido, Santos (1980) destaca a criação em 1964 do programa de pesquisa Inter-University Research Program in Institution Building, integrado por universidades americanas. A partir do programa, foram produzidas diversas pesquisas de caráter aplicado que se preocuparam em prescrever as formas como uma organização poderia se tornar uma instituição e sobreviver no mundo dos negócios.

$\mathrm{Na}$ década de 70, o institucionalismo assumiu uma abordagem diferente, buscando resgatar a importância dos sistemas cognitivos e do sentido simbólico para o estudo das organizações. Segundo Angonese (2012), o "novo institucionalismo" provocou uma ruptura com a forma convencional de se pensar a estrutura organizacional, ao procurar destacar a influência do ambiente e o papel da cultura na formação, no aperfeiçoamento e na similaridade das organizações.

A tese do construtivismo social de Berger e Luckmann é considerada o principal fundamento do neoinstitucionalismo (PECI, 2006). Para Berger e Luckmann (2004), as instituições são resultantes de um processo em que as ações se tornam habituais adquirindo uma condição de valor ao longo do tempo. A habitualidade é adquirida no curso de uma história, e não instantaneamente, de modo que para entender adequadamente uma instituição é preciso compreender o processo histórico em que foi produzida (SELZNICK, 1971; BERGER; LUCKMANN, 2004).

A análise realizada por Meyer e Rowan é considerada o marco inicial do novo institucionalismo (ALVES, 2012). A ideia central do estudo é a de que a pressão recebida pela organização para atender às expectativas externas é determinante na escolha dos arranjos estruturais. Nessa ótica, a busca por sobrevivência levaria as organizações a incorporarem elementos legitimados externamente, independente da eficiência imediata gerada com a adoção da estrutura (MEYER; ROWAN, 1999).

Segundo Tolbert e Zucker (1998), até se tornarem institucionalizadas, as organizações passam por um processo que se divide em três estágios sequenciais: habitualização (préinstitucionalização), objetificação (semi-institucionalização) e sedimentação (total institucionalização). A fase da habitualização tem início com inovações e mudanças efetuadas em resposta a problemas organizacionais específicos. Nessa fase, também chamada de préinstitucionalização, as organizações buscam formalizar as atividades com base nos problemas que surgem no decorrer da administração. Para solucionar os problemas, são levados em conta 
políticas e procedimentos adotados e testados em outras organizações, havendo possibilidade de mimetismo (TOLBERT; ZUCKER, 1998). Gomes et al. (2013) destacam que na fase de habitualização a organização está na tentativa de desenvolver procedimentos padronizados para a manutenção e o funcionamento das atividades organizacionais.

Nesse estágio, ainda não há consenso entre os gestores sobre a eficácia da nova estrutura, que é limitada em termos de operação e, geralmente, pouco permanente, por vezes durando apenas o período de uma gestão. Não se verifica atividade de teorização a fim de propagar a estrutura na organização ou entre as organizações, não havendo conhecimento da estrutura por parte de não adotantes (TOLBERT; ZUCKER, 1998).

A fase de objetificação se caracteriza pela disseminação da estrutura, que passa a ter seu significado socialmente compartilhado na organização e pelo desenvolvimento de certo grau de consenso social entre os gestores sobre sua eficácia. Nessa fase, considerada de semiinstitucionalização, se observa frequente atividade de teorização por grupos de interesse, buscando atribuir à estrutura legitimidade cognitiva e normativa (TOLBERT; ZUCKER, 1998).

No estágio de semi-institucionalização as organizações adotantes costumam ser bastante heterogêneas, dificultando possíveis associações entre as características das organizações e a adoção de uma determinada estrutura. No entanto, na medida em que a teorização se desenvolve, a variação na forma como a estrutura é implementada vai diminuindo. Também como reflexo da atividade de teorização, o ímpeto de difusão da estrutura deixa de ocorrer exclusivamente por processos miméticos e passa a ter uma base mais normativa. Apesar de ter adquirido certo grau de aceitação normativa, ainda haverá incerteza em relação à efetividade da estrutura, já que possui, via de regra, uma história relativamente curta (TOLBERT; ZUCKER, 1998).

A última etapa do processo de institucionalização é a fase de sedimentação, que se caracteriza pela institucionalização total da estrutura. A fase de sedimentação está fundamentada na continuidade da estrutura, ou seja, na sua sobrevivência ao longo dos anos na organização. Nesse estágio, a difusão da estrutura é virtualmente completa, tanto pela sua propagação no ambiente, como pela sua perpetuação, implicando assim "bidimensionalidade" (largura e profundidade).

Para Tolbert e Zucker (1998), a total institucionalização decorre dos efeitos em conjunto de uma baixa resistência de grupos de oposição, do apoio continuado de grupos 
defensores e da correlação positiva com resultados esperados. Nessa fase, os valores, procedimentos, práticas e normas relacionados à forma organizacional são absorvidos como verdades, estando livres de questionamentos (GOMES et al., 2013).

Na visão de Machado-da-Silva e Gonçalves (1998), o tratamento estático dispensado às fases do processo de institucionalização com a utilização dos termos "pré", "semi" e "total" merece ser nuançado. Para os autores as fases do processo não obedecem necessariamente a uma ordem sequencial estática, podendo ocorrer de forma simultânea ou até se repetirem ao longo do tempo.

\section{PROCEDIMENTOS METODOLÓGICOS}

Essa pesquisa classifica-se como qualitativa e descritiva. Do ponto de vista dos procedimentos metodológicos, a pesquisa assumiu a forma de estudo de caso, conforme o proposto por Yin (2015). Seguindo a orientação do mesmo autor, elaborou-se um protocolo do estudo de caso englobando os objetivos delineados, os procedimentos utilizados para coleta de dados, esclarecimentos sobre a participação das pessoas envolvidas na pesquisa, bem como as regras e compromissos estabelecidos.

A fim de preservar a imagem da Universidade em estudo, o anonimato da Instituição e dos sujeitos envolvidos na pesquisa foi assegurado. Assim, no decorrer do estudo, a Instituição pesquisada foi identificada apenas como "Instituição/Universidade analisada ou em estudo". Em relação ao marco temporal, a pesquisa apresenta corte seccional, com perspectiva longitudinal abrangendo desde a implantação da auditoria interna na Instituição analisada até o ano de 2018, quando foi realizado o trabalho de campo.

Para alcançar o objetivo da pesquisa foram estabelecidas categorias e subcategorias de análise a partir do referencial teórico adotado. A operacionalização das subcategorias ocorreu por meio de entrevistas e, adicionalmente, por meio de análise documental. A seleção dos sujeitos da pesquisa foi realizada de forma intencional e motivada pelo acesso às informações necessárias para o alcance do objetivo do estudo.

As entrevistas foram realizadas entre os meses de junho e julho de 2018. Participaram da pesquisa quatro integrantes da atual equipe e um ex-integrante da Auditoria Interna, identificados nesse estudo pelo termo "Auditor" seguido dos numerais de 1 a 5 . O grupo de gestores participantes da pesquisa incluiu o Chefe de Gabinete do Reitor e os oito Pró- 
Reitores da Universidade, identificados ao longo do estudo pelo termo "Gestor" acompanhado dos numerais de 1 a 9 .

A entrevista mais longa durou 40 minutos e foi realizada com o Auditor 3, enquanto que as entrevistas de menor duração, com 12 minutos cada, foram realizadas com os Gestores 1 e 8 . As entrevistas foram gravadas com a autorização dos entrevistados e totalizaram 353 minutos de áudio.

As entrevistas foram do tipo semiestruturada, ou seja, foram conduzidas com o apoio de um roteiro que, apesar de orientar o processo, não tirou a liberdade de terem sido acrescentadas questões pelo entrevistador (MARTINS; THEÓPHILO, 2016). Antes de dar início às entrevistas na Universidade em análise, realizou-se o pré-teste dos instrumentos de coleta de dados em uma universidade com características similares, por meio de entrevistas com o Chefe da Auditoria Interna e com o Pró-Reitor de Planejamento e Administração. A partir da análise da transcrição das entrevistas realizadas no pré-teste, os roteiros elaborados na pesquisa puderam ser refinados com a inclusão, supressão e reformulação de algumas questões.

Além das entrevistas, foram analisados documentos oficiais da Universidade em estudo. A coleta documental foi empreendida com a finalidade de confirmar, esclarecer e complementar os dados obtidos nas entrevistas. Para análise dos dados foi utilizada como técnica principal a análise de conteúdo, definida por Bardin (1977) como um conjunto de técnicas e instrumentos metodológicos aplicados ao discurso tendo em comum o emprego da inferência. Em consonância com a técnica escolhida, o processo de análise do material compreendeu as seguintes etapas sequenciais: pré-análise, descrição analítica e interpretação inferencial.

Assim, em um primeiro momento, realizou-se a transcrição das entrevistas anteriormente gravadas. Durante a transcrição, que resultou em 73 páginas de texto, foi efetuada a análise preliminar dos dados, procedimento denominado por Bardin (1977) como leitura flutuante. Nessa fase, foram registradas as primeiras impressões sobre os textos das entrevistas.

Em seguida, teve início a fase de análise propriamente dita com a codificação dos dados da pesquisa. Nessa etapa, partes dos textos provenientes das entrevistas e da pesquisa documental foram relacionadas às categorias e subcategorias de análise previamente 
estabelecidas a partir da literatura. A codificação foi realizada com o apoio do software para análise textual Atlas.ti versão 8.

$\mathrm{Na}$ terceira e última etapa, o material coletado foi explorado com maior profundidade, tratado e interpretado com a ajuda de elementos gráficos (redes) resultantes da codificação realizada no software. A Figura 1 exemplifica uma das redes criadas através do software.

Figura 1 Rede da categoria "Fase de Habitualização"

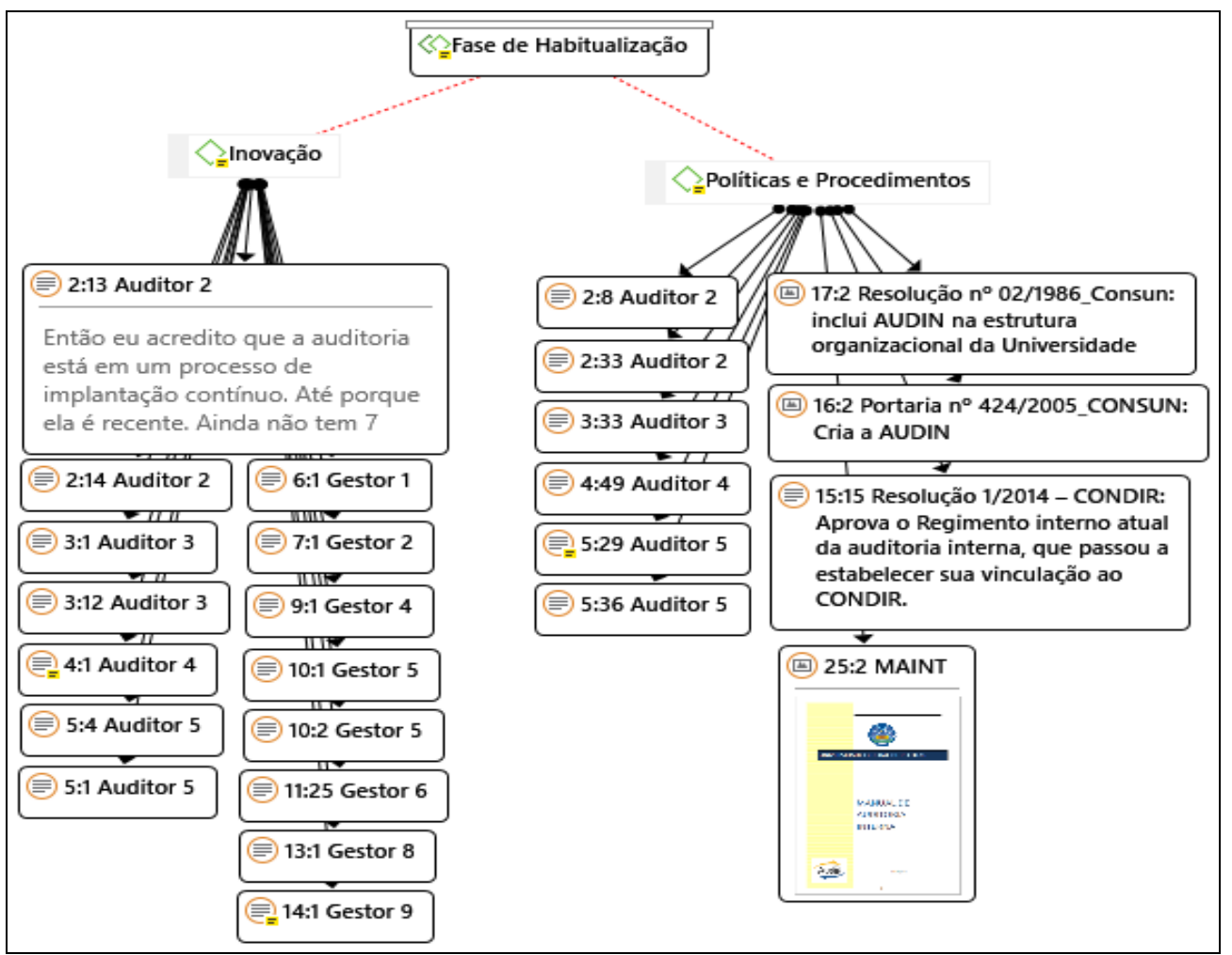

Fonte: Dados da pesquisa

Conforme evidencia a Figura 1, as redes criadas no Atlas.ti explicitam a relação existente entre os dados provenientes das entrevistas e da pesquisa documental e os códigos, facilitando a análise e permitindo a elaboração de conclusões.

\section{RESULTADOS}

\subsection{FASE DE HABITUALIZAÇÃO}

A fase de habitualização corresponde ao estágio de pré-institucionalização da estrutura. Para analisar essa fase do processo foram adotadas as subcategorias "Inovação" e "Políticas e Procedimentos". 
Em relação à subcategoria "Inovação", verificou-se que a maioria dos entrevistados, englobando auditores (3 citações) e gestores (7 citações), percebe a Auditoria Interna como uma estrutura recente na Universidade. Nesse sentido, afirmou o Auditor 2 "[...] então eu acredito que a auditoria está em um processo de implantação contínuo. Até porque ela é recente. Ainda não tem sete anos".

Outro fato interessante é que a percepção da Auditoria Interna também pode variar de acordo com a natureza da atividade dos atores sociais envolvidos. Segundo apurado nas entrevistas, há uma maior tendência de a AUDIN ser percebida como uma estrutura nova nas unidades acadêmicas do que nas unidades administrativas. Reforça esse ponto de vista o fato de alguns gestores terem revelado que tiveram conhecimento da Auditoria Interna somente quando passaram a exercer o cargo de gestão, embora já estivessem trabalhando há vários anos como docentes na Universidade (2 citações).

Ainda no tocante à subcategoria "Inovação", verificou-se que a atuação da AUDIN não ocorre somente quando surgem problemas no decorrer da administração. Segundo o relato dos auditores, as atividades são realizadas de forma sistemática e mediante planejamento (4 citações), embora também haja a possibilidade de auditorias extraordinárias (1 citação) e sejam oferecidas atividades de consultoria à alta gestão (3 citações).

No que diz respeito à subcategoria "Políticas e Procedimentos", observou-se que a Auditoria Interna está em processo de normalização já adiantado, estando regularmente instituída e possuindo regimento interno e manual de procedimentos devidamente formalizados na Universidade. No entanto, identificou-se a necessidade de atualizar tais documentos de acordo com as normas que regem a atividade, especialmente com as emitidas pela CGU (4 citações). Nas palavras do Auditor 4 "Nós temos um manual de auditoria interna e temos um regimento interno, mas ambos estão desatualizados. Isto porque a partir de 2015 vieram muitas instruções normativas".

Da análise das subcategorias "Inovação" e "Políticas e Procedimentos", percebe-se que embora a AUDIN ainda seja percebida como uma estrutura nova pela maioria dos entrevistados, as atividades do setor são desenvolvidas de forma organizada, planejada e sistemática, estando as atribuições e procedimentos normatizados na Universidade.

De acordo com o modelo proposto por Tolbert e Zucker, a fase de habitualização tem início com a adoção de novos arranjos estruturais, utilizados em resposta a problemas organizacionais momentâneos e específicos. Nesse estágio, os novos arranjos ainda não estão 
normalizados na organização (TOLBERT; ZUCKER, 1998). Desta forma, entende-se que a Auditoria Interna em estudo apresenta pouca aderência às características da fase de habitualização.

\subsection{FASE DE OBJETIFICAÇÃO}

A fase de objetificação se refere ao estágio de semi-institucionalização da estrutura. Para verificar o alinhamento da Auditoria Interna às características desta fase do processo foram selecionadas as subcategorias "Teorização" e "Disseminação e Consenso Social".

Conforme Tolbert e Zucker (1998), a fase de objetificação é caraterizada por haver acentuada atividade de teorização, definida como o empenho em conferir legitimidade normativa e cognitiva à estrutura. Nesse ponto, verifica-se que, diferente do que se observou no período de implantação e nos anos seguintes, atualmente não há atividade consistente de teorização. As entrevistas com os auditores revelaram que atividades procurando mostrar para a organização a importância e os benefícios gerados pela AUDIN são realizadas apenas durante as reuniões para elaboração do PAINT (3 citações) e em reuniões no decorrer das ações de auditoria (2 citações).

Ainda nesse aspecto, destaca-se o fato de o regimento interno e o manual de procedimentos estarem pendentes de um processo de atualização, o que também pode ser considerado como indicativo de uma baixa atividade de teorização.

A compreensão das finalidades da AUDIN pelos atores sociais envolvidos, bem como a percepção sobre a eficácia da atividade foi explorada por meio da subcategoria "Disseminação e Consenso Social". De acordo com Tolbert e Zucker (1998), no estágio de objetificação observa-se a disseminação da estrutura que passa a ter seu significado socialmente compartilhado na organização.

Em relação aos gestores participantes da pesquisa, verificou-se que a maioria ( 8 citações) percebe o trabalho da AUDIN com caráter de orientação e de auxílio.

\footnotetext{
Então cada vez mais tem que se tirar essa imagem fiscalizatória. A auditoria tem que manter a independência dela, mas deve atuar mais nesse sentido, de informação. E eu acho que a nossa auditoria interna aqui na [...] tem atuado muito nesse sentido, que é um sentido de bom relacionamento com os gestores (Gestor 7).
}

Apenas o Gestor 3 expressou uma visão diferente, ao declarar que "Eu não falo como gestor, mas como membro da comunidade que vejo muito mais como fiscalização". Ao 
contrário do verificado nesse estudo, na pesquisa de Bordin (2015), os resultados mostraram que a atividade de auditoria interna ainda era entendida pela maioria dos gestores como de fiscalização e como forma de inibir sua autonomia.

É importante ressalvar que, embora declarem ter uma concepção diferente, os gestores percebem que a visão que predomina entre os demais servidores da Universidade, é ainda de uma auditoria com cunho de fiscalização. $\mathrm{Na}$ opinião dos gestores, a visão distorcida é decorrente do desconhecimento sobre o papel da AUDIN na Instituição (7 citações).

Eu já notei uma certa confusão ou uma preocupação excessiva interna com a auditoria por achar que a auditoria exerce o papel de fiscalizador e punitivo em alguns casos (Gestor 5).

Segundo Tolbert e Zucker (1998), na fase de objetificação também é possível observar certo consenso entre os gestores sobre a eficácia da estrutura. Nesse ponto, nota-se que já há um entendimento compartilhado entre os gestores sobre os benefícios que podem ser obtidos com a atuação da Auditoria Interna, notadamente no que tange ao seu caráter preventivo (5 citações).

Eu brinco que é mais ou menos como uma consciência crítica, vive fazendo um monitoramento para que a gente possa sempre estar desenvolvendo as atividades de uma forma adequada e sem que existam possibilidades de que aquilo se torne um problema para a instituição. Então acho que isso é um mecanismo de controle do serviço que acaba melhorando a qualidade do mesmo (Gestor 3).

Em síntese, verifica-se que, embora já exista consenso sobre a eficácia da AUDIN, percebe-se que sua disseminação ainda é restrita na Instituição. Além disso, não se observa atividade acentuada de teorização, que é uma das características da fase semi-institucional. Desta forma, entende-se que a AUDIN analisada apresenta uma aderência moderada às características da fase de objetificação.

\subsection{FASE DE SEDIMENTAÇÃO}

A fase de sedimentação corresponde ao estágio de total institucionalização da estrutura. Para verificar a aderência da AUDIN às características dessa fase foram estabelecidas as subcategorias "Continuidade da Estrutura", "Resistência de Grupos Opositores" e "Resultados Obtidos".

Para Tolbert e Zucker (1998), a total institucionalização de uma estrutura está apoiada em sua continuidade histórica. De forma similar ao estudo realizado por Alves, Castro e Souto 
(2013), na análise da subcategoria "Continuidade da Estrutura" buscou-se verificar se a Auditoria Interna reúne as condições necessárias para sua sobrevivência na Universidade. Foram analisados aspectos relacionados aos elementos físicos, tecnológicos e humanos disponibilizados à AUDIN.

Em relação aos materiais, equipamentos e espaço físico, os auditores entrevistados entendem que a estrutura oferecida é suficiente para desenvolver os trabalhos com qualidade (4 citações). Nesse sentido, afirmou, por exemplo, o Auditor 4 " [...] a gente tem uma boa sala, temos equipamentos que são suficientes para o nosso trabalho, inclusive agora estamos recebendo uma impressora nova". A situação encontrada se contrapõe à verificada nos estudos de Santana (2013), Shulz (2014) e Bordin (2015), que ao analisarem auditorias internas em instituições de ensino federais identificaram a existência de dificuldades em termos de estrutura física e de recursos humanos.

No que tange aos elementos tecnológicos, a equipe de auditoria se mostrou satisfeita com os equipamentos disponibilizados (4 citações), porém foi externada a necessidade de acesso a programas e sistemas de informação para melhor desempenho das atribuições (3 citações). Em relação ao quadro funcional, verificou-se que o quantitativo de servidores e a formação técnica do grupo são considerados satisfatórios (4 citações).

Por outro lado, no que diz respeito à capacitação dos servidores, o estudo identificou a necessidade de melhorias (3 citações). Nas palavras do Auditor 5 "Ultimamente, a questão da capacitação não tem sido atendida por falta de recursos financeiros". No mesmo sentido, declarou o Auditor 3 que "no quesito de treinamento eu acho que deveríamos ter um planejamento melhor de capacitação”. Em consonância com o que foi relatado nas entrevistas, a análise dos últimos três RAINTs mostra que a AUDIN não vem atendendo ao número mínimo de 40 horas de treinamento por servidor recomendado pela CGU (CGU, 2017).

Quando questionada sobre a possibilidade de descontinuidade ou enfraquecimento da AUDIN na Instituição, a equipe de auditoria acredita que a extinção do setor não é viável, especialmente por sua exigência legal (4 citações), mas reconhece a possibilidade de enfraquecimento, sobretudo devido à dependência de apoio da gestão (4 citações). Segundo o Auditor 2 "o enfraquecimento sim é possível porque não tem uma estabilidade ainda. Como eu já falei, depende muito do gestor" 
Aspectos referentes ao relacionamento com os gestores, considerado um ponto nevrálgico da atividade (CASTRO, 2011; SCHULZ, 2014), foram investigados na subcategoria "Resistência de Grupos Opositores". Nesse quesito, buscou-se não apenas identificar a existência de mobilização coletiva contrária à AUDIN, mas também de possíveis focos de resistência na Universidade, na ótica dos entrevistados. Conforme o modelo de análise proposto por Tolbert e Zucker (1998), a total institucionalização está diretamente relacionada a uma baixa resistência de grupos opositores.

$\mathrm{Na}$ opinião dos integrantes da Auditoria Interna, o relacionamento com a gestão está em processo de melhoria constante, existindo cada vez mais receptividade ao trabalho desenvolvido. Verifica-se que a equipe não enfrenta dificuldade para ter acesso aos objetos auditados e que tem suas solicitações, via de regra, atendidas pela gestão (4 citações). No que concerne à independência e autonomia para desempenhar as atividades, atributos indispensáveis para eficácia da auditoria interna (CASTRO, 2011), percebe-se que há liberdade para conduzir os trabalhos (4 citações) e certa clareza em relação à independência da gestão (1 citação).

Nesse ponto, é possível notar que houve avanço nas condições de trabalho da equipe de auditoria, a julgar pela dificuldade de obter respostas da gestão e falta de independência e autonomia identificadas em períodos anteriores, notadamente em razão de sua subordinação ao Reitor, e não ao CONDIR, como se verifica atualmente. Além disso, pode-se inferir que a demora em criar efetivamente o setor, formalmente instituído em 1986 e implantado apenas em 2010, sugere que existiam na Universidade forças contrárias à adoção da estrutura.

Reforçando o argumento de Castro (2011), a crescente intensificação dos processos de responsabilização dos gestores na Administração Pública foi indicada como um fator que tem contribuído para a aceitação do trabalho realizado pela AUDIN, na medida em que traz segurança para o próprio gestor. Na percepção do Auditor 3 “ [...] os gestores estão cada vez mais sendo responsabilizados, cada vez mais sendo levados a responder pelos seus atos. Então vai se instalar essa cultura, de ver os beneficios da auditoria interna".

Nas entrevistas com os gestores não foram observados sinais claros de resistência ao trabalho desenvolvido pela AUDIN. As declarações dos gestores demonstram que não é oferecida oposição da parte deles às ações de auditoria. Ao ser questionado sobre o assunto, o Gestor 6 foi categórico afirmando que "em relação à atual gestão eu tenho 100\% de certeza que não tem resistência alguma". Expressando o mesmo entendimento, declarou o Gestor 4 
que "da nossa parte não, pelo contrário. Nós entendemos a nossa auditoria como parceira de trabalho".

As entrevistas com os gestores também demonstraram o impacto positivo de duas práticas adotadas no relacionamento entre auditores e auditados: a realização da Reunião de Busca Conjunta de Soluções ( 2 citações) e a forma de elaboração do PAINT (5 citações). Nas palavras do Gestor 7" a reunião de busca de conjunta de soluções foi legal porque a gente verificou que o problema não era aqui, que era durante todo o processo [...]. É uma questão de escutar todos os lados".

A partir de 2016, a elaboração do Plano de Atividades da Auditoria Interna (PAINT) passou a contar com a participação dos gestores da alta administração da Universidade. No PAINT são definidas as ações de auditoria a serem realizadas no ano seguinte. Baseada na filosofia do risco (CASTRO, 2011), a construção do PAINT leva em conta parâmetros previamente definidos para a escolha dos processos a serem auditados.

No entanto, embora demonstrem aceitação em relação ao trabalho da AUDIN, alguns gestores reconhecem a existência de um sentimento de rejeição à auditoria dentre os demais servidores da Universidade, especialmente nas unidades acadêmicas (4 citações).

A partir de certo nível, os gestores não têm mais resistência porque já conhecem o trabalho da auditoria. Mas quando entram novos gestores, eles não sabem muitas vezes o que é a auditoria e a comunidade geral da Instituição eu acho que não sabe o que é auditoria. [...] eu acho que para alta administração está ok, a auditoria é bem vista. De pró-reitores até ao nível de coordenação (Gestor 7).

$\mathrm{Na}$ visão destes gestores, também compartilhada por alguns auditores entrevistados, o sentimento negativo está associado ao desconhecimento dos reais propósitos da atividade. Igualmente, os estudos de Teixeira, Cabral, Braga e Soares (2007) e Marçola (2011) mostram que a falta de esclarecimento sobre o papel da auditoria interna acentua a rejeição do auditado.

Segundo a percepção do Gestor 5, o posicionamento de defesa também está relacionado a um instinto natural do ser humano que tende a rejeitar ser fiscalizado.

Quando se fala em auditoria, seja interna ou externa, isso já assusta. Eu entendo que há algo em torno do trabalho de auditoria que gera insegurança para o servidor e para o gestor. Acho que isso é natural. Algumas pessoas se sentem intimidadas ou invadidas, essa é a verdade. [...] acabo eu explicando para os servidores que a auditoria interna é uma parceira, e não alguém que veio punir. Ela vai nos precaver para que não tenhamos problemas (Gestor $5)$. 
O relato do Gestor 5 fortalece o entendimento de Castro (2011), que atribui a resistência à auditoria a uma questão sociológica. Para o autor, as pessoas tendem a se sentir tolhidas e expostas ao vexame ao terem suas falhas apontadas, o que pode se agravar quando o auditado é uma pessoa que tem dificuldade em aceitar críticas.

Conforme o Gestor 1, um meio de aprimorar a relação entre auditor e auditado, seria buscar consolidar o entendimento de que o tempo despendido no desenvolvimento das ações de auditoria se reverte no fortalecimento da gestão e em benefícios para a Universidade. Nessa perspectiva, cabe destacar a observação feita pelo Gestor 6 .

[...] é, mais acompanhamento porque no início da auditoria pedem informações disso, disso e disso, daí fornecemos as informações e os dados. Mas qual foi o resultado? Quais foram as consequências de todo aquele trabalho? O que a gente conseguiu melhorar? Não sei, de repente tendo um dado mais concreto pode dar uma motivação maior (Gestor 6).

$\mathrm{Na}$ opinião do Gestor 6, como modo de incentivar os gestores, a AUDIN poderia ampliar o processo de acompanhamento das recomendações emitidas, transcendendo o momento da implementação e buscando identificar os impactos positivos gerados com o atendimento das recomendações.

$\mathrm{O}$ índice de atendimento das recomendações é um aspecto diretamente relacionado à efetividade da AUDIN. Esse e outros aspectos referentes ao desempenho do setor são abordados a seguir, na última e terceira subcategoria da fase de sedimentação, que corresponde aos "Resultados Obtidos". A análise se fundou na percepção de auditores e gestores e em relatórios e levou em conta as atividades de avaliação e de consultoria realizadas pela AUDIN. Segundo o processo de institucionalização pensado por Tolbert e Zucker (1998), a total institucionalização possui correlação positiva com os resultados desejados.

Quando questionados em relação ao atingimento dos resultados esperados pelo setor, apenas o Auditor 2 disse não saber responder. Na concepção dos Auditores 3, 4 e 5, a Auditoria Interna está conseguindo alcançar seus objetivos. No entanto, foi observada a necessidade de melhorar o índice de implementação das recomendações emitidas pelo setor. Nesse sentido, ponderou o Auditor 5 que "Eu acredito que os trabalhos proporcionam esses resultados, só que a gente ainda tem uma implementação das recomendações mediana. No último RAINT consta que a implementação é de $50 \%$. Na verdade, nem chega a 50\%." 
Em consonância com as declarações dos Gestores 1 e 6, no ponto de vista do Auditor 5, o nível de implementação poderia ser elevado com o aprimoramento das práticas relacionadas ao acompanhamento das recomendações.

Acredito que reuniões periódicas com os gestores para avaliar o atendimento das recomendações poderia aumentar o nível de implementação [...]. Eu me refiro a algo que pudesse melhorar a comunicação com os gestores em relação a situação das recomendações (Auditor 5).

A situação do total de recomendações emitidas pela AUDIN em 2015 e em 2016 foi extraída do RAINT/2017. Das 106 recomendações emitidas em 2015 e em 2016, 46 foram implementadas, 53 estão em fase de implementação e 7 não foram implementadas. Nota-se que, embora esteja sendo alcançado um nível moderado de implementação, inferior a 50\%, em relação à ampla maioria das recomendações emitidas percebe-se que já estão sendo tomadas providências ou que, no mínimo, há disposição do gestor em atendê-las, já que as recomendações atendidas e em processo de implementação somadas representam $90 \%$ das recomendações.

No que concerne à atividade de consultoria realizada pela AUDIN, especialmente pelo chefe da unidade, os auditores relataram que se trata de um serviço frequentemente requisitado pelos gestores (3 citações). A percepção dos auditores se alinha à declaração do Gestor 1, que revelou procurar seguidamente a AUDIN para aconselhamento, ao afirmar que “[...] justamente nesses assessoramentos, em dúvidas nesse sentido de encaminhamentos, de busca por legislação, de questionar se o procedimento está correto. Eu utilizo muito a assessoria da auditoria".

Desta forma, diante do cenário identificado a partir da análise das subcategorias estabelecidas, pode-se inferir que a Auditoria Interna em estudo apresenta aderência moderada à fase de sedimentação do processo de institucionalização pensado por Tolbert e Zucker (1998).

\section{CONSIDERAÇÕES FINAIS}

Este estudo teve por objetivo analisar o processo de institucionalização da auditoria interna em uma universidade federal, com apoio do modelo proposto por Tolbert e Zucker (1998). Em síntese, diante dos resultados e partindo da premissa de que as fases não possuem necessariamente uma ordem sequencial-estática (MACHADO-DA-SILVA; GONÇALVES, 
1998), considera-se que a Auditoria Interna em estudo possui aderência baixa ao estágio de habitualização e moderada aos estágios de objetificação e de sedimentação.

A partir da análise das subcategorias "Inovação" e "Políticas e Procedimentos", relacionadas à fase de habitualização, verificou-se que a atuação da Auditoria Interna ocorre de forma organizada, planejada e sistemática e que suas atribuições já estão normatizadas na Universidade. Contudo, nesse aspecto, identificou-se a necessidade de atualizar o regimento interno e o manual de procedimentos do setor.

Para analisar a aderência da Auditoria Interna à fase de objetificação, foram estabelecidas as subcategorias "Teorização" e "Disseminação e Consenso Social". Em relação à subcategoria "Teorização", observou-se que, ao contrário do que se verificou em períodos anteriores, atualmente há baixa atividade buscando conferir legitimidade normativa e cognitiva à Auditoria Interna.

Analisando a subcategoria "Disseminação e Consenso Social", identificou-se a existência de um entendimento socialmente compartilhado sobre a eficácia da estrutura dentre os gestores da alta administração, que já percebem a atuação da AUDIN com viés de orientação, e não de fiscalização.

A Fase de Sedimentação foi analisada a partir das subcategorias "Continuidade da estrutura", "Resistência de Grupos Opositores" e "Resultados Obtidos". Em relação à primeira subcategoria, verificou-se que o setor conta com estrutura física adequada e com recursos humanos suficientes, havendo, porém, a necessidade de aprimorar o processo de capacitação dos servidores e de ampliar o acesso a programas e sistemas de informação.

No que diz respeito à subcategoria "Resistência de Grupos Opositores", verificou-se que a equipe de auditoria percebe que a relação com os auditados está em processo de melhoria constante. A percepção positiva foi confirmada pelos gestores da alta administração, que demonstraram não oferecer oposição ao trabalho desenvolvido pela AUDIN.

No entanto, alguns gestores relataram a existência de uma visão distorcida sobre a Auditoria Interna que gera certo temor e um sentimento de rejeição em níveis hierárquicos inferiores, entre os demais servidores e, especialmente, nas unidades acadêmicas da Universidade. Alinhando-se aos resultados de pesquisas anteriores (TEIXEIRA et al., 2007; MARÇOLA, 2011; BORDIN, 2015), o estudo indica que o desconhecimento sobre a atuação da Auditoria Interna acentua o posicionamento de defesa dos auditados. Por isso, acredita-se 
que seriam importantes ações no sentido de esclarecer os reais propósitos da atividade e as formas de atuação da AUDIN.

No tocante à subcategoria "Resultados Obtidos", percebe-se que a AUDIN acompanhou a modernização da atividade ocorrida nos últimos anos, especialmente ao direcionar o foco para os resultados organizacionais, buscando melhorar a eficiência da gestão e a qualidade dos serviços prestados pela Instituição. Acredita-se que um modo de incentivar os gestores, potencializando os resultados da auditoria, seria investir no processo de acompanhamento das recomendações, transcendendo o momento da implementação e buscando demonstrar os impactos positivos para a Instituição.

Por fim, cabe destacar que o estudo demonstrou a aplicabilidade do modelo analítico desenvolvido por Tolbert e Zucker (1998) para o tipo de estrutura analisada, uma vez que direcionou a análise para pontos cruciais que afetam o desenvolvimento institucional das auditorias internas.

Para pesquisas futuras, sugere-se que a análise empreendida nesse estudo, baseada na Teoria Institucional, seja expandida para outras auditorias internas inseridas na Administração Pública Indireta, não apenas por meio de estudos de caso único, como este, mas também por meio de estudos comparativos e estudos multicaso.

\section{REFERÊNCIAS}

ALVES, R. R. A institucionalização dos cursos de Administração Pública a distância das universidades públicas: os casos UFLA e UFU. 2012. 196 f. Dissertação (Mestrado em Administração) - Universidade Federal de Lavras, Lavras, 2012.

ANGONESE, R. O processo de mudança no sistema de contabilidade gerencial: análise da implementação de sistemas integrados de gestão sob a ótica da teoria institucional. 2012. 228 f. Tese (Doutorado em Ciências Contábeis e Administração) - Universidade Regional de Blumenau, Blumenau, 2012.

BARDIN, L. Análise de conteúdo. Lisboa: Edições 70, 1977.

BERGER, P. L.; LUCKMANN, T. A Construção Social da Realidade: tratado de sociologia do conhecimento. Petrópolis: Vozes, 2004.

BORDIN, T. M. Avaliação das auditorias internas no âmbito da gestão de instituições públicas federais de ensino Superior (IFES): um exame crítico de seu funcionamento e efeitos. 2015. 144 f. Dissertação (Mestrado em Educação) - Universidade Federal da Fronteira Sul, Chapecó, 2015. 
BRASIL. Constituição República Federativa do Brasil, de 05 de outubro de 1988.

Disponível em: <http://www.planalto.gov.br/ccivil_03/constituicao/constituicao.htm>. Acesso em: 13 mai. 2017.

BRASIL. Decreto $\mathbf{n}^{\mathbf{0}}$ 3.591, de 06 de setembro de 2000. Dispõe sobre o Sistema de Controle Interno do Poder Executivo Federal e dá outras providências. Disponível em:

$<$ http://www.planalto.gov.br/ccivil_03/decreto/d3591.htm>. Acesso em: 13 mai. 2017.

CASTRO, D. P. Auditoria, contabilidade e controle interno no setor público. São Paulo: Atlas, 2011.

CHIARINI, T.; VIEIRA, K. P. Universidades como produtoras de conhecimento para o desenvolvimento econômico: sistema superior de ensino e as políticas de CT\&I. Revista Brasileira de Economia, v. 66, n. 1, p. 117-132, 2012.

DIMAGGIO, P. J; POWELL, W. W. El nuevo institucionalismo en el análisis organizacional. Fondo de Cultura Económica, 1999.

GOMES, A. O.; PETER, M. G. A.; MACHADO, M. V. V.; OLIVEIRA, T. E. A Institucionalização da Controladoria no Âmbito do Poder Executivo Municipal no Estado do Ceará. Revista Contabilidade, Gestão e Governança, Brasília, v. 16, n. 1, p. 35-50, 2013.

JEPPERSON, R. Instituciones, efectos institucionales e institucionalismo. In: DIMAGGIO, P. J; POWELL, W. W. El nuevo institucionalismo en el análisis organizacional. Fondo de Cultura Económica, 1999.

LINCZUK, L. M. W. Governança aplicada à administração pública - a contribuição da auditoria interna para sua efetivação: um estudo em universidades públicas federais. 2012. 181 f. Dissertação (Mestrado em Planejamento e Governança Pública) - Universidade Tecnológica Federal do Paraná, Curitiba, 2012.

MACHADO-DA-SILVA, C. L., GONÇALVES, S. A., Nota Técnica: A Teoria Institucional. In: CLEGG, S. R.; HARDY, C.; NORD, W. R. Handbook de Estudos Organizacionais, v. 1, São Paulo: Atlas, 1998.

MARÇOLA, C. Auditoria interna como instrumento de controle social na administração pública. Revista do Serviço Público - RSP, Brasília, v. 62, n.1, p.75-87, 2011.

MARTINS, G. A., THEÓPHILO, C. R. Metodologia da Investigação Científica para Ciências Sociais Aplicadas. São Paulo: Atlas, 2016.

MEYER, J. W.; B. ROWAN. Organizaciones institucionalizadas: la estrutura formal como mito y cerimonia. In: DIMAGGIO, P. J; POWELL, W. W. El nuevo institucionalismo en el análisis organizacional. Fondo de Cultura Económica, 1999.

MINISTÉRIO DA TRANSPARÊNCIA, FISCALIZAÇÃO E CONTROLADORIA-GERAL DA UNIÃO - CGU. Instrução Normativa Conjunta MP/CGU nº 01, de 11 de maio de 2016. Disponível em: <http://www.cgu.gov.br/sobre/legislacao/arquivos/instrucoesnormativas/in_cgu_mpog_01_2016.pdf>. Acesso em: 22 set. 2017. 
MINISTÉRIO DA TRANSPARÊNCIA, FISCALIZAÇÃO E CONTROLADORIA-GERAL DA UNIÃO. Instrução Normativa n⿳ 24, de 17 de novembro de 2015. Disponível em: $<$ http://www.cgu.gov.br/sobre/legislacao/arquivos/instrucoesnormativas/in_cgu_24_2015.pdf $>$. Acesso em: 18 dez. 2017.

MINISTÉRIO DA TRANSPARÊNCIA, FISCALIZAÇÃO E CONTROLADORIA-GERAL DA UNIÃO. Instrução Normativa n⿳0 03, de 09 de junho de 2017. Disponível em: $<\mathrm{http}$ :/www.cgu.gov.br/sobre/legislacao/arquivos/instrucoesnormativas/in_cgu_03_2017.pdf $>$. Acesso em: 18 dez. 2017.

MINISTÉRIO DA TRANSPARÊNCIA, FISCALIZAÇÃO E CONTROLADORIA-GERAL DA UNIÃO. Manual de Orientações Técnicas da Atividade de Auditoria Interna Governamental do Poder Executivo Federal. Brasília: CGU, 2017.

MINISTÉRIO DA TRANSPARÊNCIA, FISCALIZAÇÃO E CONTROLADORIA-GERAL DA UNIÃO. Portaria no 915, de 29 de abril de 2014. Disponível em:

$<$ http://www.cgu.gov.br/sobre/legislacao/arquivos/portarias/portaria_cgu_915_2014.pdf $>$. Acesso em: 18 dez. 2017.

PECI, A. A nova teoria institucional em estudos organizacionais: uma abordagem crítica. Cadernos EBAPE, Rio de Janeiro, v. 4, n. 1, p. 1-12, 2006.

SANTANA, P. M. F. R. Sistema de controle interno: estudo de caso sobre um Instituto Federal de Educação, Ciência e Tecnologia na perspectiva da eficiência da gestão. 2013.158 f. Dissertação (Mestrado em Administração Pública) - Universidade Federal de Lavras, Lavras, 2013.

SANTOS, G. B. Desenvolvimento institucional: uma estratégia. Revista de Administração Pública - RAP. Rio de Janeiro, v. 14, n. 3, p. 5-18, 1980.

SCHULZ, J. P. A função controle em uma instituição federal de ensino superior: um estudo de caso da auditoria interna. 2014. 172 f. Dissertação (Mestrado em Administração). Universidade Federal de Santa Catarina. Florianópolis, 2014.

SELZNICK, P. A liderança na administração. Rio de Janeiro: FGV, 1971.

SOUZA, A. A.; MARQUES, A. M. F.; OLIVEIRA, L. F.; GLÓRIA, L. G. L.; BRAGA, A. S. Análise do sistema de controle interno e da auditoria interna em hospitais públicos e filantrópicos. Revista Tourism \& Management Studies, Faro, v. 3, p. 896-906, 2013.

TEIXEIRA, J. C.; CABRAL, A. C. A.; BRAGA, R. E. C.; SOARES, R. T. O Processo de Institucionalização da Atividade de Auditoria da Controladoria Geral do Município de Fortaleza: Uma Análise Incipiente sob o Enfoque da Teoria Institucional. In: Encontro da Associação Nacional de Pós-Graduação e Pesquisa em Administração, 31, Rio de Janeiro, 2007. Anais... ANPAD: Rio de Janeiro, 2007. 
TOLBERT, P. S.; ZUCKER, L. A institucionalização da teoria institucional. In: CLEGG, S. R.; HARDY, C.; NORD, W. R. Handbook de Estudos Organizacionais, v. 1, São Paulo: Atlas, 1998.

YIN, R. K. Estudo de Caso: Planejamento e Métodos. Porto Alegre: Bookman, 2015. 